Check for updates

Cite this: RSC Adv., 2017, 7, 45697

Received 4th August 2017

Accepted 16th September 2017

DOI: $10.1039 / c 7 r a 08618 k$

rsc.li/rsc-advances

\section{Regioisomer effects of [70]PCBM on film structures and photovoltaic properties of composite films with a crystalline conjugated polymer $\mathrm{P} 3 \mathrm{HT} \uparrow$}

\author{
Tomokazu Umeyama, (D) *a Sho Shibata, ${ }^{a}$ Tetsushi Miyata, ${ }^{a}$ Kensho Igarashi, ${ }^{a}$ \\ Tomoyuki Koganezawa ${ }^{\mathrm{b}}$ and Hiroshi Imahori (iD *ac
}

\begin{abstract}
Despite the wide prevalence of [6,6]-phenyl- $C_{71}$-butyric acid methyl ester ([70]PCBM) as an electron acceptor in high-performance organic photovoltaic (OPV) devices, [70]PCBM has been generally used as a mixture of regioisomers. In this study, we utilized regioisomerically pure $\alpha$ - and $\beta$-[70]PCBM in combination with a crystalline conjugated polymer donor, poly(3-hexylthiophene) (P3HT) to investigate systematically the regioisomer effects of [70]PCBM on structures and electronic and photovoltaic properties of the composite films. Notably, the $\beta$-isomer induced a face-on P3HT packing in the blend film, whereas an edge-on alignment of P3HT was observed in the composite films with the $\alpha$-isomer as well as the regioisomer mixture (mix-[70]PCBM). The hole mobility in a vertical direction to the substrate in the P3HT: $\beta$-[70]PCBM film was higher than those in P3HT: $\alpha$-[70]PCBM and P3HT:mix-[70]PCBM due to the face-on P3HT packing. Reflecting the superior hole mobility, the OPV device based on the P3HT: $\beta$-[70]PCBM film showed a higher power conversion efficiency of $3.69 \%$ than the devices based on the other composite films (3.11-3.21\%). The results obtained here demonstrate that the use of regioisomerically pure [70]fullerene mono-adducts can modulate the polymer packing direction in the blend film, which is an unprecedented approach to improve the device performances of OPVs.
\end{abstract}

\section{Introduction}

Conversion of solar power to electricity has emerged as a highly promising solution to world's increasing energy demands. Although commercialized solar cells are currently dominated by silicon- and other inorganic compound semiconductor-based devices, ${ }^{1-4}$ bulk heterojunction $(\mathrm{BHJ})$ organic photovoltaic (OPV) devices consisting of electron-donating conjugated polymers and electron-accepting organic semiconductors have recently attracted tremendous scientific and industrial attention due to the advantages of a simple device structure, lightweight, low-cost, and the possibility of being fabricated into flexible devices. ${ }^{5-8}$ Fullerene derivatives have been widely utilized as an electron-accepting material in OPVs because of their strong electron-deficient character and excellent semiconducting properties originated from their small

${ }^{a}$ Department of Molecular Engineering, Graduate School of Engineering, Kyoto University, Nishikyo-ku, Kyoto 615-8510, Japan.E-mail: umeyama@scl.kyoto-u.ac.jp; imahori@scl.kyoto-u.ac.jp; Fax: +81-75-383-2571; Tel: +81-75-383-2568; +81-75383-2566

${ }^{b} J a p a n$ Synchrotron Radiation Research Institute (JASRI), SPring-8, 1-1-1 Kouto, Sayo, Hyogo 679-5198, Japan

'Institute for Integrated Cell-Material Sciences (WPI-iCeMS), Kyoto University, Nishikyo-ku, Kyoto 615-8510, Japan

$\dagger$ Electronic supplementary information (ESI) available. See DOI: 10.1039/c7ra08618k reorganization energies of electron transfer, ${ }^{9}$ whereas nonfullerene electron acceptors, exhibiting high power conversion efficiencies (PCEs), have recently emerged as alternatives. ${ }^{\mathbf{1 0 - 1 3}}$ Specifically, [70]fullerene derivatives such as [6,6]-phenyl- $\mathrm{C}_{71^{-}}$butyric acid methyl ester ([70]PCBM) are preferentially employed in high-performance OPVs compared to [60]fullerene derivatives owing to their better light-harvesting ability in visible region and higher solubility in organic solvents. ${ }^{\mathbf{1 4 , 1 5}}$ However, even mono-addition reactions to $\mathrm{C}_{70}$ generally yield a mixture of regioisomer products as the result of the low symmetry of $\mathrm{C}_{70}$ cage $\left(D_{5 \mathrm{~h}}\right)$, while the same additions to $\mathrm{C}_{60}$ with the high symmetry $\left(I_{\mathrm{h}}\right)$ generate a single product. A $\mathrm{C}_{70}$ cage has four different types of non-equivalent $[6,6]$-bonds, i.e., $\alpha-, \beta-, \varepsilon^{-}$, (a)

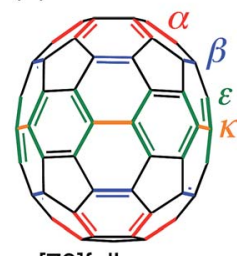

[70]fullerene (b)

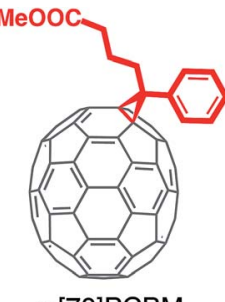

$\alpha-[70]$ PCBM

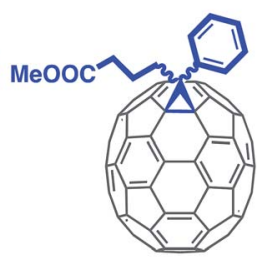

$\beta$-[70]PCBM
Fig. 1 Structures of (a) [70]fullerene and (b) [70]PCBM isomers. $\alpha-, \beta-$, $\varepsilon^{-}$, and $\kappa$-type $[6,6]$-bonds of [70]fullerene are represented by red, blue, green and orange lines in (a). 
$\kappa$-type bonds (Fig. 1a). It is known that [70]PCBM prepared by a conventional method using 4-benzoylbutyrate tosylhydrazone and $\mathrm{C}_{70}$ contains $\alpha$-type isomer (80-90\%) and $\beta$-type one (1020\%) (Fig. 1b). ${ }^{\mathbf{1 4}, \mathbf{1 6}-21}$ Although the difference in the regioisomers affects the device performances, [70]PCBM is usually used as the regioisomer mixture in OPVs because of the difficulty of their separation and purification in a large scale.

Recently, by using a special high-performance liquid chromatography (HPLC) suitable for the separation of fullerenes, we separated as-purchased [70]PCBM (denoted as mix-[70]PCBM) into regioisomerically pure $\alpha$ - and $\beta$-[70]PCBM in a large quantity and investigated the regioisomer effects on the photovoltaic properties for the first time. ${ }^{\mathbf{1 6}}$ In combination with an amorphous conjugated polymer PCDTBT (poly $\left[N-9^{\prime}\right.$-heptadecanyl-2,7-carbazole-alt-5,5-(4', $7^{\prime}$-di-2-thienyl-2' $, 1^{\prime}, 3^{\prime}$-benzothiadiazole)]), the pure [70]PCBM regioisomers led to higher PCEs of $6.20 \%$ for $\alpha$-[70]PCBM and $6.46 \%$ for $\beta$-[70]PCBM than that of $5.59 \%$ for mix-[70]PCBM, demonstrating that the use of the single regioisomers of [70]PCBM can cause a positive effect on the photovoltaic properties. Meanwhile, Martín and coworkers selectively synthesized $\alpha$-[70]PCBM by a reaction between a diazonium compound and $\mathrm{C}_{70}$ and found that the OPV device based on a crystalline conjugated polymer PffBT4T$2 \mathrm{OD}$ (poly[(5,6-difluoro-2,1,3-benzothiadiazol-4,7-diyl)-alt-(3,3"' di(2-octyldodecyl)-2,2'; $5^{\prime}, 2^{\prime \prime} ; 5^{\prime \prime}, 2^{\prime \prime \prime}$-quaterthiophen-5, $5^{\prime \prime \prime}$-diyl)]) and $\alpha$-[70]PCBM showed a comparable PCE $(6.63 \%)$ to that of the device with PffBT4T-2OD and mix-[70]PCBM (6.45\%). ${ }^{20}$ Moreover, Zhan et al. reported that $\alpha$ - and $\beta-[70]$ PCBM, in combination with a relatively amorphous conjugated polymer PTB7 (poly[[4,8-bis[(2-ethylhexyl)oxy]benzo[1,2- $b$ :4,5- $\left.b^{\prime}\right]$ dithiophene-2,6-diyl][3-fluoro-2-[(2-ethylhexyl)carbonyl]thieno[3,4- $b]$ thiophenediyl]]), exhibited PCEs of $6.04 \%$ and $5.05 \%$, respectively, which are inferior to that of mix-[70]PCBM $(7.44 \%)$, implying that the single regioisomers of [70]PCBM do not always provide a better device performance than mix-[70] PCBM. ${ }^{18}$ It was suggested that the differences in molecular packing in the fullerene domains and the phase separation structures in the blend films, which are significantly dependent on the isomerism of [70]PCBM, exerted a substantial impact on the photovoltaic properties. ${ }^{\mathbf{1 6 , 1 8}}$ Nevertheless, investigations of the regioisomer effect of [70]fullerene mono-adducts on OPV device performances are still extremely limited, and thus remain to be solved.

Regioregular poly(3-hexylthiophene) (P3HT) is a prototypical conjugated polymer donor in BHJ OPVs as a consequence of the easy synthesis and good processability. ${ }^{22-26}$ P3HT has a highly crystalline nature and thereby the $\mathrm{P} 3 \mathrm{HT}$ film shows an excellent charge carrier mobility. ${ }^{27}$ An epoch-making PCE value more than $4 \%$ was attained in 2005 with combination of [6,6]-phenyl$\mathrm{C}_{61}$-butyric acid methyl ester ([60]PCBM). ${ }^{24-26} \mathrm{P} 3 \mathrm{HT}$ is currently replaced by various kinds of donor-acceptor alternating conjugated polymers with low bandgaps in highly efficient single-cell type OPVs, ${ }^{5-8}$ because the wide bandgap of the P3HT film limits the wavelength region of its light-harvesting $(<650 \mathrm{~nm})$. Nevertheless, considering its inexpensive commercial availability, P3HT has not still lost its value in OPV researches $^{28}$ and widely used in tandem devices to achieve high
PCE values ${ }^{29-31}$ and in model systems to investigate the device mechanisms. ${ }^{32-37}$

In this study, we utilized the highly crystalline P3HT as an electron donor polymer and $\alpha_{-}, \beta-$, and mix-[70]PCBM as an electron acceptor to examine the regioisomer effect of [70]PCBM on OPV device performances. Systematic investigations of regioisomer effects on structures and electronic properties of the P3HT:[70]PCBM blend films were also conducted. Note here that OPV devices based on the blend film of P3HT and the regioisomer mixture of [70]PCBM have already been reported. ${ }^{38-40}$ In addition, there have been the reports of the [70] PCBM isomer effects in the blend films with PCDTBT, ${ }^{\mathbf{1 6}}$ PffBT4T-2OD, ${ }^{18}$ and PTB7 (ref. 20) on the photovoltaic properties (vide supra). However, this is the first example of the combination of P3HT and the regioisomerically pure [70]PCBM.

\section{Experimental}

\section{Instruments}

Regioisomer separation of [70]PCBM was conducted by Shimadzu Prominence Modular HPLC with Nacalai Tesque Cosmosil buckyprep $(20 \times 250 \mathrm{~mm})$; eluent, toluene; flow rate, 10 $\mathrm{mL} \min ^{-1}$; detection, $330 \mathrm{~nm}$. UV-visible absorption spectra were obtained on a Perkin Elmer Lambda 900UV/vis/NIR spectrometer. Steady-state fluorescence spectra were recorded on a HORIBA SPEX Fluoromax-3 spectrofluorometer. Atomic force microscopy (AFM) analyses were carried out with an Asylum Technology MFP-3D-SA in the AC mode. Photocurrent-voltage characteristics were measured by Keithley 2400 SourceMeter under a nitrogen atmosphere and simulated solar light (100 $\mathrm{mW} \mathrm{cm}^{-2}$, AM1.5) with OTENTO-SUN III solar simulator (Bunkoukeiki). Photocurrent action spectra were recorded with CEP-2000RR (Bunkoukeiki). Current-voltage characteristics of the electron- and hole-only devices for space-charge-limited current (SCLC) measurements were conducted using Keithley 2400 SourceMeter under an argon atmosphere.

\section{Materials}

[70]PCBM (>99.0\%) and P3HT (regioregular) were purchased from American Dye Source, Inc. and Sigma-Aldrich, respectively. All other solvents and chemicals were of reagent-grade quality, purchased commercially, and used without further purification unless otherwise noted.

\section{Separation of [70]PCBM isomers}

Separation of a regioisomer mixture of [70]PCBM $(60.0 \mathrm{mg})$ was accomplished by HPLC with a Buckyprep column at $50{ }^{\circ} \mathrm{C}$ using toluene as an eluent. ${ }^{16} \alpha$-Type isomer $(\alpha$-[70]PCBM, $52.6 \mathrm{mg}$, yield $87.7 \%$ ), $\beta$-type isomer ( $\beta$-[70]PCBM, $7.2 \mathrm{mg}$, yield $12.0 \%$ ), and an impurity [60]PCBM $(0.2 \mathrm{mg}, 0.3 \%)$ were obtained.

\section{Device fabrications}

Indium tin oxide (ITO) on a glass substrate with a sheet resistance of $5 \Omega \mathrm{sq}^{-1}$ (Geomatec) was used. The substrate was sonicated consecutively with water, chloroform, acetone, semico clean (Furuuchi Chemical), 2-propanol, and ethanol. After 
blow-drying and UV-ozone treatment, $0.2 \mathrm{M}$ zinc acetate dihydrate $\left(\mathrm{Zn}\left(\mathrm{CH}_{3} \mathrm{COO}\right)_{2} \cdot 2 \mathrm{H}_{2} \mathrm{O}\right)$ solution in 2-methoxyethanol with 1 vol\% of ethanolamine was spin-coated onto the substrates at $4000 \mathrm{rpm}$ for $20 \mathrm{~s}$. The substrate was dried in an oven at $200{ }^{\circ} \mathrm{C}$ for $10 \mathrm{~min}$ to prepare the ITO/ZnO substrate. For the fabrication of the active layer, a mixed solution of P3HT $\left(25 \mathrm{mg} \mathrm{mL}^{-1}\right)$ and [70]PCBM isomers $\left(25 \mathrm{mg} \mathrm{mL}^{-1}\right.$ ) in $o$-dichlorobenzene (ODCB) was spin-coated at $1000 \mathrm{rpm}$ onto ITO/ZnO. Then, thermal annealing of the active layer was conducted at $150{ }^{\circ} \mathrm{C}$ for $10 \mathrm{~min}$. The film thicknesses of P3HT: $\alpha-[70]$ PCBM, P3HT: $\beta$-[70]PCBM and P3HT:mix-[70]PCBM were 229, 211, and $228 \mathrm{~nm}$, respectively. After spin-coating of active layer, $\mathrm{MoO}_{3}(10 \mathrm{~nm})$ and $\mathrm{Au}$ $(70 \mathrm{~nm})$ were sequentially deposited to obtain the OPV device denoted as ITO/ZnO/P3HT:[70]PCBM/ $/ \mathrm{MoO}_{3} / \mathrm{Au}$.

The hole-only device was fabricated as follows. The substrate was sonicated consecutively with acetone, ethanol, water, semico clean (Furuuchi Chemical) and 2-propanol. After blowdrying and UV-ozone treatment, the substrate was spin-coated at $1000 \mathrm{rpm} / 4000 \mathrm{rpm}$ with PEDOT:PSS and dried with a hot plate at $200{ }^{\circ} \mathrm{C}$. The P3HT:fullerene blend film with the same ratio as in the OPV device was spin-coated at $800 \mathrm{rpm}$. Then, thermal annealing of the active layer was conducted at $150{ }^{\circ} \mathrm{C}$ for $10 \mathrm{~min}$. After annealing, the active layer was capped by a $100 \mathrm{~nm}$ Au electrode. Meanwhile, the electron-only device was fabricated as follows. A $50 \mathrm{~nm}$ Al film was first thermally deposited onto the glass substrate. The P3HT:fullerene blend film was spin-coated at $800 \mathrm{rpm}$. Then, the active layer was capped by a $100 \mathrm{~nm} \mathrm{Al}$ electrode.

\section{GISAXS and GIWAXS}

The sample was prepared by spin-coating the P3HT:fullerene solution on a glass substrate with the same concentrations as in the OPV device fabrications. Grazing-incidence small-angle Xray scattering (GISAXS) and grazing-incidence wide-angle X-ray scattering (GIWAXS) measurements were conducted at the SPring-8 on beamline BL46XU. For the GISAXS measurements, the sample was irradiated at a fixed incident angle on the order of $0.12^{\circ}$ through a Huber diffractometer with an X-ray energy of $8.00 \mathrm{keV}$ (X-ray wavelength $\lambda=0.155 \mathrm{~nm}$ ), and the GISAXS patterns were recorded with a $2 \mathrm{D}$ image detector (Pilatus $2 \mathrm{M}$ ) with a sample-to-detector distance of $3022 \mathrm{~mm}$. GISAXS intensity profiles in the lower- $q$ region contributed by fullerene aggregates in the P3HT:fullerene blend films were modeled with Debye-Anderson-Brumberger (DAB) equation, ${ }^{\mathbf{1 6 , 4 1 , 4 2}}$

$$
I(q)=\frac{A}{\left\{1+(q L)^{2}\right\}^{2}}
$$

with scattering intensity $I$, constant $A$, scattering vector $q$, and correlation length $L$. For the GIWAXS measurements, the sample was irradiated at a fixed incident angle on the order of $0.12^{\circ}$ through a Huber diffractometer with an X-ray energy of $12.4 \mathrm{keV}$ (X-ray wavelength $\lambda=0.100 \mathrm{~nm}$ ), and the GIWAXS patterns were recorded with a $2 \mathrm{D}$ image detector (Pilatus $300 \mathrm{~K}$ ) with the sample-to-detector distance of $173.8 \mathrm{~mm}$.

\section{Solubility tests}

The solubilities of $\alpha-[70]$ PCBM, $\beta$-[70]PCBM and mix-[70]PCBM in ODCB were estimated as follows. ${ }^{43}$ Saturated solutions of the fullerene materials were prepared by adding an excess amount of the fullerenes to ODCB, followed by sonication at room temperature for $1 \mathrm{~min}$. Then, the saturated solutions were filtered through a membrane filter (Cosmonice Filter S, COSMOSIL, pore size: $0.45 \mu \mathrm{m}$ ) to remove the aggregates. The amounts of the fullerene materials dissolved in the filtrates were determined by weighing the solid contents that remained after evaporation of the solvent and thorough drying under vacuum.

\section{Results and discussion}

The regioisomerically pure $\alpha$-[70]PCBM and $\beta$-[70]PCBM were isolated from mix-[70]PCBM containing $12 \mathrm{wt} \% \beta-[70] \mathrm{PCBM}$ and $88 \mathrm{wt} \% \alpha$-[70]PCBM by the HPLC technique with Buckyprep column, as conducted in our previous study. ${ }^{16} \beta-[70]$ PCBM has two types of diastereomers, ${ }^{\mathbf{1 4 , 1 6 , 1 8 , 1 9}}$ but they were unable to be separated by the Buckyprep column ${ }^{\mathbf{1 6}}$ and used as the diastereomer mixture. Then, we prepared P3HT:[70]PCBM isomer films from the $o$-dichlorobenzene (ODCB) solution $(1: 1, \mathrm{w} / \mathrm{w})$ onto the ITO/ZnO substrate with thermal annealing at $150{ }^{\circ} \mathrm{C}$ for $10 \mathrm{~min}$, which is the optimized condition for the OPV devices. The surface morphologies of P3HT: $\alpha-[70]$ PCBM, P3HT: $\beta$-[70]PCBM, and P3HT:mix-[70]PCBM films were assessed by atomic force microscopy (AFM) measurements (Fig. 2). The morphologies are similar to each other and the root-mean-square (rms) surface roughnesses are comparable (8.2-9.0 nm, Table 1), indicating that there are no significant differences in the domain sizes of the $\mathrm{BHJ}$ blend films. In addition, all the blend films show no micrometer-sized
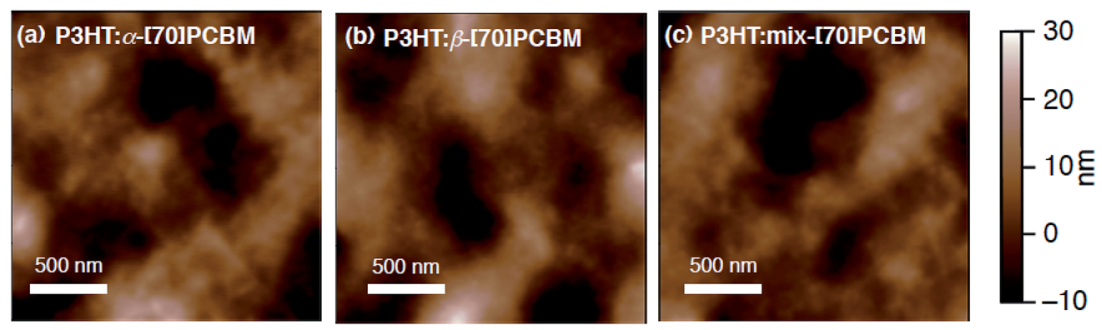

Fig. 2 AFM images of (a) P3HT: $\alpha$-[70]PCBM, (b) P3HT: $\beta$-[70]PCBM, and (c) P3HT:mix-[70]PCBM on ITO/ZnO substrates. The color scale represents the height topography, with bright and dark representing the highest and lowest features, respectively. 
Table 1 Surface roughnesses (rms), correlation lengths $(L)$, and electron and hole mobilities ( $\mu_{\mathrm{e}}$ and $\mu_{\mathrm{h}}$ ) of the P3HT:fullerene blend films

\begin{tabular}{lllll}
\hline Fullerene & $\begin{array}{l}\mathrm{rms}^{a} \\
(\mathrm{~nm})\end{array}$ & $\begin{array}{l}L^{b} \\
(\mathrm{~nm})\end{array}$ & $\begin{array}{l}\mu_{\mathrm{h}}{ }^{c} \\
\left(10^{-5} \mathrm{~cm}^{2} \mathrm{~V}^{-1} \mathrm{~s}^{-1}\right)\end{array}$ & $\begin{array}{l}\mu_{\mathrm{e}}{ }^{c} \\
\left(10^{-5} \mathrm{~cm}^{2} \mathrm{~V}^{-1} \mathrm{~s}^{-1}\right)\end{array}$ \\
\hline$\alpha-[70]$ PCBM & 9.0 & 33.3 & 0.49 & 1.0 \\
$\begin{array}{l}\beta-[70] \text { PCBM } \\
\text { mix-[70] }\end{array}$ & 8.2 & 33.3 & 1.3 & 1.2 \\
PCBM & 8.6 & 33.0 & 0.29 & 0.83 \\
& & & &
\end{tabular}

${ }^{a}$ The values of rms obtained from AFM measurements. ${ }^{b}$ Correlation lengths based on the Debye-Anderson-Brumberger model from onedimensional GISAXS profiles. ${ }^{c}$ Mobilities determined by SCLC method.

aggregates which cause negative effects on the photovoltaic properties. ${ }^{1,44}$ The GISAXS measurements were also conducted to estimate the statistically averaged fullerene domain sizes. Crystal long period $(L)$ of P3HT calculated from the correlation peaks in the Lorentz-corrected scattering pattern in low scattering vector $(q)$ amplification corresponds to the fullerene domain sizes. ${ }^{45}$ The $L$ of $33.3 \mathrm{~nm}$ for P3HT: $\alpha$-[70]PCBM, $33.3 \mathrm{~nm}$ for P3HT: $\beta-[70] \mathrm{PCBM}$, and $33.0 \mathrm{~nm}$ for P3HT:mix-[70]PCBM are comparable (Fig. S1 $\uparrow$ and Table 1 ). These results also suggest that the difference in the regioisomers of [70]PCBM has little impact on the domain sizes in the composite films with P3HT.

To obtain insight into the interchain packing structure of P3HT in the composite films, the GIWAXS measurements were also carried out (Fig. 3). The GIWAXS profiles of the P3HT: $\alpha-[70]$ PCBM and P3HT:mix-[70]PCBM blend films after the thermal annealing exhibit significant out-of-plane (l00) and in-plane (010) reflection patterns, indicating a well-organized lamellar structure oriented edge-on with the substrate (Fig. $3 \mathrm{~d}$ and f). ${ }^{26}$ This result is consistent with previous reports ${ }^{46,47}$ that the spincoating from a solvent with a high boiling point such as ODCB $\left(180^{\circ} \mathrm{C}\right)$ tends to form the thermodynamically favored edge-on structure of P3HT. Comparing to the GIWAXS profiles of the as-
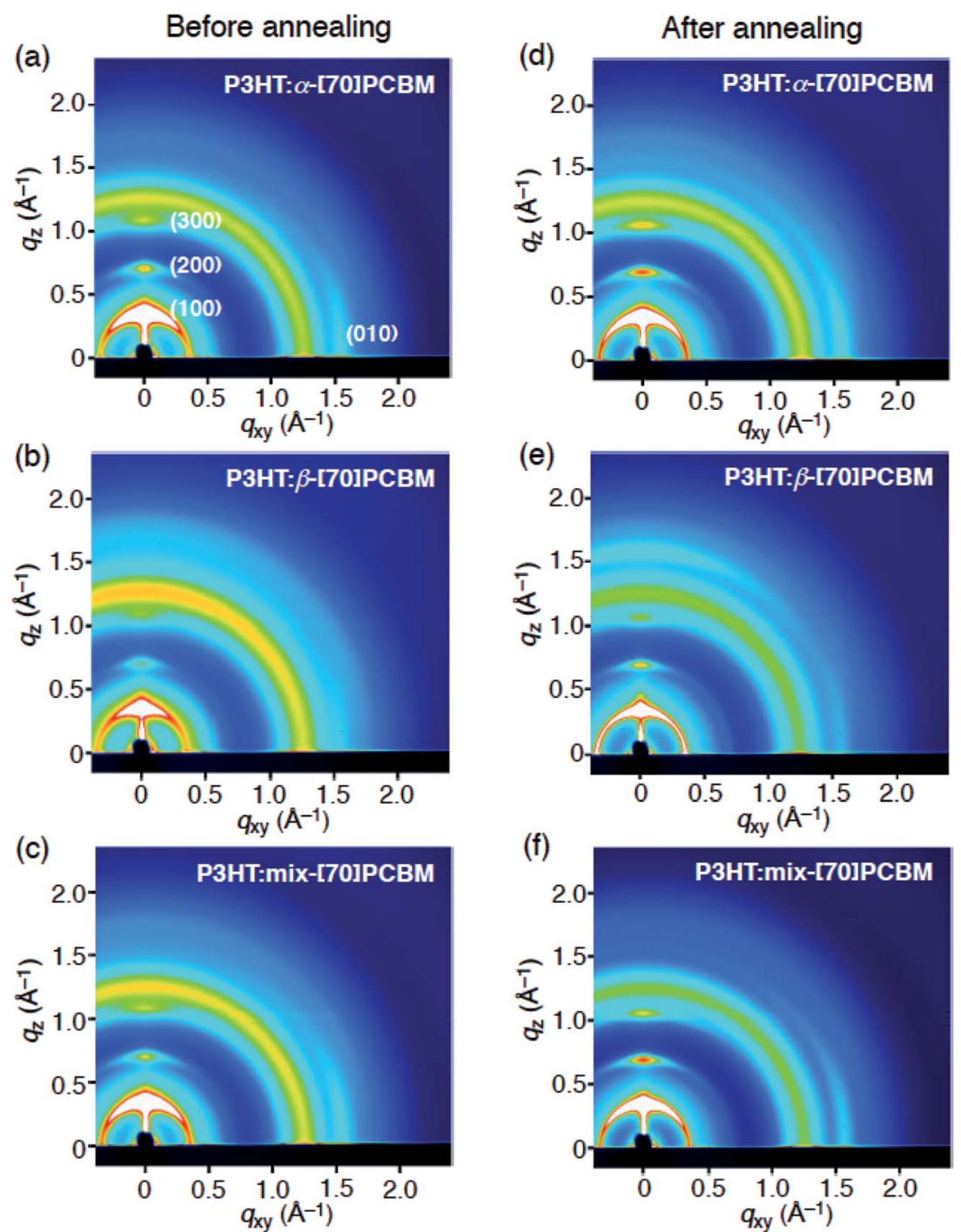

Fig. 3 Two dimensional GIWAXS plots of P3HT:fullerene blend films (a-c) before and (d-e) after annealing. $(a, d) \alpha-[70] P C B M,(b, e) \beta-[70] P C B M$, and $(\mathrm{c}, \mathrm{f}) \mathrm{mix}-[70] \mathrm{PCBM}$. 


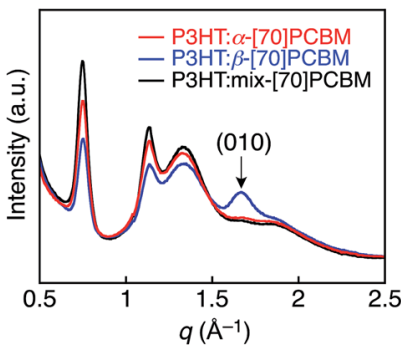

Fig. 4 Vertical line cuts of the two dimensional GIWAXS plots of P3HT: $\alpha$-[70]PCBM (red), P3HT: $\beta$-[70]PCBM (blue), and P3HT:mix-[70] PCBM (black) films after annealing. The peak position of the (010) reflection is indicated with an arrow in the figure.

prepared films (Fig. 3a and c), the edge-on orientations are enhanced by the thermal annealing in P3HT: $\alpha-[70] \mathrm{PCBM}$ and P3HT:mix-[70]PCBM.

Notably, the P3HT: $\beta-[70]$ PCBM film after the thermal annealing unambiguously displays out-of-plane (010) reflection pattern (Fig. 3e and 4), which is absent in the other composite films. The thermal annealing procedure induces the face-on packing structure of P3HT, while no clear out-of-plane (010) signal is evident in the GIWAXS profile of the as-prepared P3HT: $\beta-[70]$ PCBM (Fig. 3b). Although it is known that the structures of polymer backbones and side chains and the processing conditions such as solvents, solvent additives, and substrate surfaces make an impact on the orientation of the polymer main chains, ${ }^{46-53}$ to the best of our knowledge, this is the first example that the difference in the regioisomers of fullerene mono-adducts alters the packing orientation of conjugated polymers in the blend films. It was reported that P3HT with low regioregularity (81\%) tends to form the face-on structure, while P3HT with high regioregularity $(>91 \%)$ the edge-on structure. ${ }^{49}$ However, the low regioregularity deteriorates the crystallinity of $\mathrm{P} 3 \mathrm{HT}$ and thereby decreases the chargetransporting ability. In addition, spin-coating using solvent with a low boiling point such as chloroform $\left(61^{\circ} \mathrm{C}\right)$ is known to form the P3HT film with the kinetically favored face-on packing structure, ${ }^{46}$ but fullerene and its derivatives generally show insufficient solubilities in low boiling point solvents for homogeneous film formation by the spin-coating method. ${ }^{54}$ Therefore, applying regioisomerically pure fullerene monoadduct isomers is the best way to form the blend film of faceon packing $\mathrm{P} 3 \mathrm{HT}$ and the isomers on various substrates. It is not surprising that the film structure of P3HT:mix-[70]PCBM is similar to that of P3HT: $\alpha-[70]$ PCBM because mix-[70]PCBM is mostly composed of $\alpha$-[70]PCBM (88\%). Although the origin of the control of polymer packing orientation by the [70]PCBM regioisomer separation is obscure at this stage, the difference in the positions of the appended group in [70]PCBM may influence the $\pi-\pi$ interaction between $\mathrm{P} 3 \mathrm{HT}$ and the rugby ball-shaped $\mathrm{C}_{70}$, resulting in the difference in the $\mathrm{P} 3 \mathrm{HT}$ packing orientations. Alternatively, the solubility of $\beta$-[70]PCBM $\left(55 \mathrm{mg} \mathrm{mL}^{-1}\right.$ in ODCB), being lower than those of $\alpha$-[70]PCBM $\left(117 \mathrm{mg} \mathrm{mL}^{-1}\right)$ and mix-[70]PCBM (108 $\left.\mathrm{mg} \mathrm{mL}^{-1}\right)$, would contribute to the faceon alignment of P3HT in the P3HT: $\beta$-[70]PCBM blend film. Although the concentrations of $\alpha-, \beta-$, and mix-[70]PCBM for the spin-coatings in the device fabrications are all $25 \mathrm{mg} \mathrm{mL}^{-1}$, the deposition of $\beta$-[70]PCBM is faster than those of $\alpha-[70]$ PCBM and mix-[70]PCBM due to the lower solubility. The faster deposition of $\beta$-[70]PCBM may accelerate the P3HT deposition during the blend film formation, yielding the kinetically favored face-on structure of P3HT. Reflecting the face-on arrangement, the hole mobility $\left(\mu_{\mathrm{h}}\right)$ of the P3HT: $\beta$-[70]PCBM film with the vertical direction to the substrate estimated by the space chargelimited current (SCLC) method is significantly high $\left(1.3 \times 10^{-5}\right.$ $\left.\mathrm{cm}^{2} \mathrm{~V}^{-1} \mathrm{~s}^{-1}\right)$ relative to those of the P3HT: $\alpha$-[70]PCBM $(0.49 \times$ $\left.10^{-5} \mathrm{~cm}^{2} \mathrm{~V}^{-1} \mathrm{~s}^{-1}\right)$ and P3HT:mix-[70]PCBM $\left(0.29 \times 10^{-5} \mathrm{~cm}^{2}\right.$ $\mathrm{V}^{-1} \mathrm{~s}^{-1}$ ) films (Table 1). The enhanced $\mu_{\mathrm{h}}$ of P3HT: $\beta$-[70]PCBM is well-balanced with its electron mobility $\left(\mu_{\mathrm{e}}=1.2 \times 10^{-5} \mathrm{~cm}^{2}\right.$ $\mathrm{V}^{-1} \mathrm{~s}^{-1}$ ), and thereby a higher collection efficiency of the photogenerated charges is anticipated ${ }^{55}$ in the OPV device based on the P3HT: $\beta$-[70]PCBM film than other blend ones.

OPV devices with a configuration of ITO/ZnO/P3HT:fullerene/ $\mathrm{MoO}_{3} / \mathrm{Au}$ were fabricated to evaluate the regioisomer effect of [70]PCBM on the photovoltaic performances of the P3HT:[70] PCBM composite films. The detailed device fabrication procedure is described in experimental section. The averaged PCE value of the OPV device based on P3HT:mix-[70]PCBM is 3.21\% (Table 2), which is comparable to the reported ones of the devices with the configuration of ITO/ZnO/P3HT:mix-[70] PCBM $/ \mathrm{MoO}_{3} /$ metal (Table S1 $\left.\uparrow\right)^{38-40}$ As shown in Fig. 5a and Table 2, the device with P3HT: $\beta$-[70]PCBM exhibits a significantly higher PCE value (3.69\%) than those of P3HT: $\alpha-[70]$ PCBM (3.11\%) and P3HT:mix-[70]PCBM (3.21\%). The superior PCE of P3HT: $\beta$-[70]PCBM is originated from the higher short circuit current density $\left(J_{\mathrm{sC}}=11.6 \mathrm{~mA} \mathrm{~cm}{ }^{-2}\right)$ and the fill factor $(\mathrm{FF}=0.574)$ than those of P3HT: $\alpha-[70] \mathrm{PCBM}\left(J_{\mathrm{SC}}=10.7 \mathrm{~mA}\right.$ $\left.\mathrm{cm}^{-2}, \mathrm{FF}=0.526\right)$ and P3HT:mix-[70]PCBM $\left(U_{\mathrm{SC}}=10.4 \mathrm{~mA}\right.$ $\left.\mathrm{cm}^{-2}, \mathrm{FF}=0.548\right)$, while the open circuit voltages $\left(V_{\mathrm{OC}}=0.552-\right.$ $0.563 \mathrm{~V}$ ) are virtually the same. In accordance with the higher $J_{\mathrm{SC}}$ of P3HT: $\beta$-[70]PCBM, incident photon-to-current efficiencies (IPCEs) of the device with P3HT: $\beta$-[70]PCBM in the 400-600 nm region are higher than those with P3HT: $\alpha-[70]$ PCBM and P3HT:mix-[70]PCBM (Fig. 5b).

In OPV devices, the conversion of photons to current involves the following fundamental steps: (1) photon absorption, (2) exciton collection at donor-acceptor interface, (3) exciton dissociation, and (4) charge collection. With regard to the steps (1) and (2), the absorption intensities are comparable (Fig. $\mathrm{S} 2 \dagger)^{56}$ and the polymer emission quenching efficiencies are

Table 2 Photovoltaic parameters of the OPV devices based on the P3HT:fullerene blend films ${ }^{a}$

\begin{tabular}{lllll} 
Fullerene & $\begin{array}{l}J_{\mathrm{SC}} \\
\left(\mathrm{mA} \mathrm{cm}^{-2}\right)\end{array}$ & $V_{\mathrm{OC}}(\mathrm{V})$ & $\mathrm{FF}$ & PCE $(\%)$ \\
\hline$\alpha-[70] \mathrm{PCBM}$ & $10.7 \pm 0.3$ & $0.552 \pm 0.005$ & $0.526 \pm 0.008$ & $3.11 \pm 0.09$ \\
$\beta-[70] \mathrm{PCBM}$ & $11.6 \pm 0.3$ & $0.554 \pm 0.006$ & $0.574 \pm 0.009$ & $3.69 \pm 0.08$ \\
mix-[70]PCBM & $10.4 \pm 0.2$ & $0.563 \pm 0.005$ & $0.548 \pm 0.009$ & $3.21 \pm 0.10$
\end{tabular}

${ }^{a}$ The photovoltaic parameters are average values from more than 8 independent experiments. 

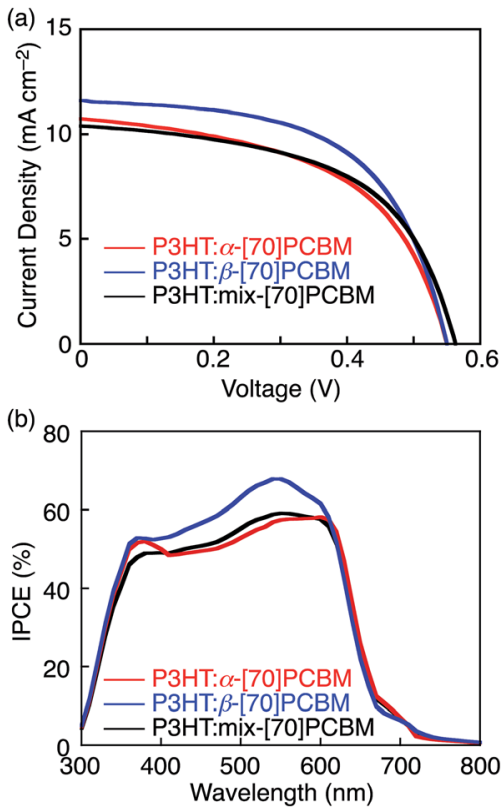

Fig. 5 (a) Current density-voltage curves and (b) photocurrent action spectra of typical OPV devices based on P3HT: $\alpha$-[70]PCBM (red), P3HT: $\beta$-[70]PCBM (blue), and P3HT:mix-[70]PCBM (black) films. The convolution of the spectral response in (b) with the photon flux of the AM 1.5G spectrum provided the estimated $J_{\text {SC }}$ values of $9.2,10.2,9.3$ $\mathrm{mA} \mathrm{cm} \mathrm{cm}^{-2}$, respectively.

sufficiently high $(>99 \%$, Fig. S3 $\uparrow$ ) in all the blend films, indicating that these steps do not make a significant difference in the $J_{\mathrm{SC}}$ values. In addition, little difference presumably exists in the exciton dissociation efficiencies of the blend films due to the sufficiently large offsets in the LUMO energy levels between P3HT $(-3.2 \mathrm{eV})^{57}$ and [70]PCBM isomers $(-3.61 \mathrm{eV}$ for $\alpha-[70]$ PCBM and $-3.66 \mathrm{eV}$ for $\beta$-[70]PCBM). ${ }^{16}$ Therefore, the superior charge collection efficiency of the device with P3HT: $\beta-[70]$ PCBM, which stems from the higher $\mu_{\mathrm{h}}$ and the well-balanced $\mu_{\mathrm{h}}$ and $\mu_{\mathrm{e}}$ values of the P3HT: $\beta$-[70]PCBM film than those of the P3HT: $\alpha-[70]$ PCBM and P3HT:mix-[70]PCBM ones, is the major factor for the higher $J_{\mathrm{SC}}$ and $\mathrm{FF}$ values of the device based on the P3HT: $\beta$-[70]PCBM one. The well-balanced, enhanced charge collection efficiency in the device with P3HT: $\beta$-[70]PCBM suppressed the space charge buildup and recombination, resulting in the improvement of $\mathrm{FF}$ as well as $J_{\mathrm{SC}}{ }^{58}$

\section{Conclusion}

In summary, regioisomer effects of [70]PCBM on film structures and electronic and photovoltaic properties of the composite films with the crystalline conjugated polymer P3HT were systematically investigated for the first time. We demonstrate here that the regioisomer of the [70]fullerene mono-adducts influences significantly the orientation of the P3HT packing alignment and thereby the hole mobility in the composite films. In the P3HT: $\beta$-[70]PCBM blend film, P3HT formed the face-on packing and showed the high hole mobility with the vertical direction to the substrate, while the edge-on structures of P3HT were made in the P3HT: $\alpha-[70]$ PCBM and P3HT:mix-[70]PCBM ones. The higher $\mu_{\mathrm{h}}$ and PCE values were achieved in the device with P3HT: $\beta$-[70]PCBM $\left(1.3 \times 10^{-5} \mathrm{~cm}^{2} \mathrm{~V}^{-1} \mathrm{~s}^{-1}\right.$ and $3.69 \%)$ than those with P3HT: $\alpha-[70]$ PCBM $\left(0.49 \times 10^{-5} \mathrm{~cm}^{2} \mathrm{~V}^{-1}\right.$ $\mathrm{s}^{-1}$ and $\left.3.11 \%\right)$ and P3HT:mix-[70]PCBM $\left(0.29 \times 10^{-5} \mathrm{~cm}^{2} \mathrm{~V}^{-1}\right.$ $\mathrm{s}^{-1}$ and $3.21 \%$ ) owing to the face-on stacking structure of P3HT. This is the first example of the face-on alignment of a conjugated polymer induced by the regioisomerically pure [70] fullerene mono-adduct in the blend film. It is known that the face-on alignment of conjugated polymers is favorable to achieve PCEs in BHJ OPV devices with relatively thick active layers $(>300 \mathrm{~nm}),{ }^{59,60}$ which are important for the industrial applications, but there are no rational guidelines for the preferable alignment. The results obtained here will provide a novel approach to achieve such high-performance OPV devices based on a crystalline conjugated polymer donor and a [70]fullerene mono-adduct derivative.

\section{Conflicts of interest}

There are no conflicts to declare.

\section{Acknowledgements}

This work was supported by JSPS KAKENHI (Grant Number JP25220501 to HI and JP26708023 and JP15H00737 to TU). The synchrotron radiation experiments for GISAXS and GIWAXS measurements were performed at the BU46XU of SPring-8 with the approval of the Japan Synchrotron Radiation Research Institute (JASRI) (Proposal No. 2014B1596).

\section{References}

1 A. Polman, M. Knight, E. C. Garnett, B. Ehrler and W. C. Sinke, Science, 2016, 352, aad4424.

2 D. Pathak, T. Wagner, T. Adhikari and J. M. Nunzi, Synth. Met., 2015, 199, 87.

3 D. Pathak, T. Wagner, T. Adhikari and J. M. Nunzi, Synth. Met., 2015, 200, 102.

4 D. Pathak and R. K. Bedi, J. Korean Phys. Soc., 2010, 56, 836.

5 T. Umeyama and H. Imahori, J. Mater. Chem. A, 2014, 2, 11545.

6 K. A. Mazzio and C. K. Luscombe, Chem. Soc. Rev., 2015, 44, 78.

7 S. Xiao, Q. Zhang and W. You, Adv. Mater., 2017, 29, 1601391. 8 Y. Cai, L. Huo and Y. Sun, Adv. Mater., 2017, 29, 1605437.

9 H. Imahori, Bull. Chem. Soc. Jpn., 2007, 80, 621.

10 C. B. Nielsen, S. Holliday, H.-Y. Chen, S. J. Cryer and I. McCulloch, Acc. Chem. Res., 2015, 48, 2803.

11 F. Zhao, S. Dai, Y. Wu, Q. Zhang, J. Wang, L. Jiang, Q. Ling, Z. Wei, W. Ma, W. You, C. Wang and X. Zhan, Adv. Mater., 2017, 29, 1700144.

12 W. Zhao, S. Li, H. Yao, S. Zhang, Y. Zhang, B. Yang and J. Hou, J. Am. Chem. Soc., 2017, 139, 7148.

13 Y. Cui, H. Yao, B. Gao, Y. Qin, S. Zhang, B. Yang, C. He, B. Xu and J. Hou, J. Am. Chem. Soc., 2017, 139, 7302. 
14 M. M. Wienk, J. M. Kroon, W. J. H. Verhees, J. Knol, J. C. Hummelen, P. A. van Hal and R. A. J. Janssen, Angew. Chem., Int. Ed., 2003, 42, 3371.

15 X. Guo, C. Cui, M. Zhang, L. Huo, Y. Huang, J. Hou and Y. Li, Energy Environ. Sci., 2012, 5, 7943.

16 T. Umeyama, T. Miyata, A. C. Jakowetz, S. Shibata, K. Kurotobi, T. Higashino, T. Koganezawa, M. Tsujimoto, S. Gélinas, W. Matsuda, S. Seki, R. H. Friend and H. Imahori, Chem. Sci., 2017, 8, 181.

17 T. Umeyama, S. Shibata, K. Igarashi, S. Takahara, T. Higashino, S. Seki and H. Imahori, Chem. Lett., 2017, 46, 1001.

18 X.-X. Zhan, X. Zhang, S.-M. Dai, S.-H. Li, X.-Z. Lu, L.-L. Deng, S.-Y. Xie, R.-B. Huang and L.-S. Zheng, Chem.-Eur. J., 2016, 22, 18709.

19 S.-M. Dai, X. Zhang, W.-Y. Chen, X. Li, Z. Tan, C. Li, L.-L. Deng, X.-X. Zhan, M.-S. Lin, Z. Xing, T. Wen, R.-M. Ho, S.-Y. Xie, R.-B. Huang and L.-S. Zheng, J. Mater. Chem. A, 2016, 4, 18776.

20 S. Vidal, M. Izquierdo, W. K. Law, K. Jiang, S. Filippone, J. Perles, H. Yan and N. Martín, Chem. Commun., 2016, 52, 12733.

21 T. Ito, Y. Inoue, T. Iwasawa, S. Sumino, F. Matsumoto, T. Iwai, K. Moriwaki, Y. Takao, T. Mizuno and T. Ohno, Synlett, 2017, 28, 1457.

22 R. S. Loewe, S. M. Khersonsky and R. D. McCullough, Adv. Mater., 1999, 11, 250.

23 T.-A. Chen and R. D. Rieke, J. Am. Chem. Soc., 1992, 114, 10087.

24 G. Li, V. Shrotriya, J. Huang, Y. Yao, T. Moriarty, K. Emery and Y. Yang, Nat. Mater., 2005, 4, 864.

25 W. Ma, C. Yang, X. Gong, K. Lee and A. J. Heeger, Adv. Funct. Mater., 2005, 15, 1617.

26 Y. Kim, S. Cook, S. M. Tuladhar, S. A. Choulis, J. Nelson, J. R. Durrant, D. D. C. Bradley, M. Giles, I. McCulloch, C.-S. Ha and M. Ree, Nat. Mater., 2006, 5, 197.

27 R. J. Kline, M. D. McGehee, E. N. Kadnikova, J. Liu, J. M. J. Fréchet and M. F. Toney, Macromolecules, 2005, 38, 3312.

28 A. T. Kleinschmidt, S. E. Root and D. J. Lipomi, J. Mater. Chem. A, 2017, 5, 11396.

29 J.-H. Kim, J. B. Park, H. Yang, I. H. Jung, S. C. Yoon, D. Kim and D.-H. Hwang, ACS Appl. Mater. Interfaces, 2015, 7, 23866.

30 W. Liu, S. Li, J. Huang, S. Yang, J. Chen, L. Zuo, M. Shi, X. Zhan, C.-Z. Li and H. Chen, Adv. Mater., 2016, 28, 9729.

31 A. Bahrami and R. Faez, Appl. Phys. A, 2017, 123, 222.

32 S. Jinnai, Y. Ie, M. Karakawa, T. Aernouts, Y. Nakajima, S. Mori and Y. Aso, Chem. Mater., 2016, 28, 1705.

33 G. D. Blanco, A. J. Hiltunen, G. N. Lim, C. B. KC, K. M. Kaunisto, T. K. Vuorinen, V. N. Nesterov, H. J. Lemmetyinen and F. D'Souza, ACS Appl. Mater. Interfaces, 2016, 8, 8481.

34 J. Razzell-Hollis, S. Limbu and J.-S. Kim, J. Phys. Chem. C, 2016, 120, 10806.

35 M. Osaka, H. Benten, H. Ohkita and S. Ito, Macromolecules, 2017, 50, 1618.
36 H. Imahori, S. Kitaura, A. Kira, H. Hayashi, M. Nishi, K. Hirao, S. Isoda, M. Tsujimoto, M. Takano, Z. Zhe, Y. Miyato, K. Noda, K. Matsushige, K. Stranius, N. V. Tkachenko, H. Lemmetyinen, L. Qin, S. J. Hurst and C. A. Mirkin, J. Phys. Chem. Lett., 2012, 3, 478.

37 T. Miura, R. Tao, S. Shibata, T. Umeyama, T. Tachikawa, H. Imahori and Y. Kobori, J. Am. Chem. Soc., 2016, 138, 5879. 38 M. Thambidurai, J. Y. Kim, J. Song, Y. Ko, N. Muthukumarasamy, D. Velauthapillai and C. Lee, Sol. Energy, 2014, 106, 95.

39 E. Polydorou, A. Zeniou, D. Tsikritzis, A. Soultati, I. Sakellis, S. Gardelis, T. A. Papadopoulos, J. Briscoe, L. C. Palilis, S. Kennou, E. Gogolides, P. Argitis, D. Davazoglou and M. Vasilopoulou, J. Mater. Chem. A, 2016, 4, 11844.

40 C. E. Song, K. Y. Ryu, S.-J. Hong, C. Bathula, S. K. Lee, W. S. Shin, J.-C. Lee, S. K. Choi, J. H. Kim and S.-J. Moon, ChemSusChem, 2013, 6, 1445.

41 H.-C. Liao, C.-S. Tsao, T.-H. Lin, C.-M. Chuang, C.-Y. Chen, U.-S. Jeng, C.-H. Su, Y.-F. Chen and W.-F. Su, J. Am. Chem. Soc., 2011, 133, 13064.

42 Y.-C. Huang, C.-S. Tsao, C.-M. Chuang, C.-H. Lee, F.-H. Hsu, H.-C. Cha, C.-Y. Chen, T.-H. Lin, C.-J. Su, U.-S. Jeng and W.-F. Su, J. Phys. Chem. C, 2012, 116, 10238.

43 T. Umeyama, S. Shibata and H. Imahori, RSC Adv., 2016, 6, 83758.

44 S. Kitaura, K. Kurotobi, M. Sato, Y. Takano, T. Umeyama and H. Imahori, Chem. Commun., 2012, 48, 8550.

45 W. Yin and M. Dadmun, ACS Nano, 2011, 5, 4756.

46 J.-F. Chang, B. Sun, D. W. Breiby, M. M. Nielsen, T. I. Sölling, M. Giles, I. McCulloch and H. Sirringhaus, Chem. Mater., 2004, 16, 4772.

47 N. Shioya, T. Shimoaka, K. Eda and T. Hasegawa, Macromolecules, 2017, 50, 5090.

48 I. Osaka and K. Takimiya, Polymer, 2015, 59, A1.

49 H. Sirringhaus, P. J. Brown, R. H. Friend, M. M. Nielsen,

K. Bechgaard, B. M. W. Langeveld-Voss, A. J. H. Spiering, R. A. J. Janssen, E. W. Meijer, P. Herwig and D. M. de Leeuw, Nature, 1999, 401, 685.

50 J.-H. Kim, S. A. Shin, J. B. Park, C. E. Song, W. S. Shin, H. Yang, Y. Li and D.-H. Hwang, Macromolecules, 2014, 47, 1613.

51 A. E. Labban, J. Warnan, C. Cabanetos, O. Ratel, C. Tassone, M. F. Toney and P. M. Beaujuge, ACS Appl. Mater. Interfaces, 2014, 6, 19477.

52 S. Shao, J. Liu, J. Zhang, B. Zhang, Z. Xie, Y. Geng and L. Wang, ACS Appl. Mater. Interfaces, 2012, 4, 5704.

53 V. Vohra, K. Kawashima, T. Kakara, T. Koganezawa, I. Osaka, K. Takimiya and H. Murata, Nat. Photonics, 2015, 9, 403.

54 C. I. Wang and C. C. Hua, J. Phys. Chem. B, 2015, 119, 14496. 55 H. Ito, T. Iwata, S. Watanabe and S. Kuroda, Appl. Phys. Express, 2013, 6, 051601.

56 The absorptions of P3HT: $\alpha-[70]$ PCBM, P3HT: $\beta-[70]$ PCBM, and P3HT:mix-[70]PCBM are over $90 \%$ in the region of 400-600 nm (Fig. S2 $\dagger$ ), which corresponds to the absorption coefficient $\alpha$ of over $1 \times 10^{5} \mathrm{~cm}^{-1}$. This value is much higher than that of intrinsic silicon $\left(9.3 \times 10^{4} \mathrm{~cm}^{-1}\right.$ at $400 \mathrm{~nm}, 1.1 \times 10^{4} \mathrm{~cm}^{-1}$ at $500 \mathrm{~nm}$, and $4.2 \times 10^{3} \mathrm{~cm}^{-1}$ 
at $600 \mathrm{~nm}$ ), although the absorption edges of the blend films are located at shorter wavelength region $(c a .670 \mathrm{~nm}$, Fig. S2 $\dagger$ ) than that of the intrinsic silicon ( $c a .1100 \mathrm{~nm})$. For the optical parameters of the intrinsic silicon, see: M. A. Green, Sol. Energy Mater. Sol. Cells, 2008, 92, 1305.

57 T. Umeyama, M. Oodoi, O. Yoshikawa, T. Sagawa, S. Yoshikawa, D. Evgenia, N. Tezuka, Y. Matano,
K. Stranius, N. V. Tkachencko, H. Lemmetyinen and H. Imahori, J. Mater. Chem., 2011, 21, 12454.

58 M.-S. Kim, B.-G. Kim and J. Kim, ACS Appl. Mater. Interfaces, 2009, 1, 1264.

59 Y. Liu, J. Zhao, Z. Li, C. Mu, W. Ma, H. Hu, K. Jiang, H. Lin, H. Ade and H. Yan, Nat. Commun., 2014, 5, 5293.

60 I. Osaka, T. Kakara, N. Takemura, T. Koganezawa and K. Takimiya, J. Am. Chem. Soc., 2013, 135, 8834. 